EDITORIAL

\title{
Statement and Commitments from SAA Editors to Change the Underrepresentation of Black, Indigenous, and Other Scholars from Diverse Backgrounds in Our Publications
}

(The SAA Publications Committee, with the assistance of Cambridge University Press, has put together materials from its publications on Race, Inequality, and Decolonization [https:// www.cambridge.org/core/societies/society-foramerican-archaeology/race-inequality-anddecolonization]. These are available without a paywall, and we also include links to other resources.)

\section{$\mathrm{T}$}

The racially based murders of George Floyd, Rayshard Brooks, Ahmaud Arbery, Breonna Taylor, and others as perpetrated by white police officers and vigilantes have brought systemic racism, anti-Black aggression, and race-based injustices perpetuated against Black Americans to the forefront of our collective consciousness. The disciplines of anthropology and archaeology are complicit in the historical basis for these events. Indigenous peoples have also experienced institutional injustices, racism, and inequalities all over the world. Archaeologists are part of this history, and as a discipline, at its core, archaeology has been a colonial practice, which has had cumulative negative effects on not only Black populations but also on Indigenous peoples and other underrepresented populations. We recognize and include these populations in our statements below and advocate for more diversity and inclusivity in the archaeology community.

The editors of the four Society for American Archaeology (SAA) publications-American Antiquity, Latin American Antiquity, Advances in Archaeological Practice, and The SAA Archaeological Record-and the editors of The SAA Press are committed to changing the underrepresentation of Black and
Indigenous scholars and other groups in our publications and to do so at all stages of the production of knowledge in our field, including teaching, mentoring, and combating structural inequity. We have, in the past, not expressly reached out to Black archaeologists and voices from other marginalized groups as much as we should. That must change and it will change. The SAA represents scholars and scholarship from around the world, from people of diverse backgrounds with diverse interests and worldviews. We understand that we cannot simply ask Black, Indigenous, and People of Color (BIPOC) scholars to take on this work but must actively take on the commitment to anti-racist and anti-colonialist structural change as individuals and as an organization.

As editors of academic journals and publications, we strive to share knowledge from our areas of interest and expertise, and we here pledge ourselves to highlight and make changes to address the deep-seated inequalities that are part of our society. Ideologies and policies rooted in racism have been central to the culture of community and opportunity in the United States since the founding of our country. This history persists in our field with many examples of structural inequality, racially driven acts of violence, denial of basic rights such as health care and education, and barriers to participation by Black people in scholarship, training, and career trajectories in archaeology. We, as professional archaeologists, need to recognize our part in the inequities that exist and work toward a more equitable state of our field.

The history of archaeology itself is in part based on colonialism, scientific racism, and 
elitism. As one example, in textbooks and lectures, archaeologists still honor Thomas Jefferson as one of the founders of American archaeology. But Jefferson was a slave owner, and he did not advocate for undoing the injustice, immorality, and violence of enslavement. We condemn this history and believe that archaeologists need to grapple with the moral complexities of the origins and development of our field.

African Americans have made other unrecognized and underappreciated contributions to American archaeology. George McJunkin, a Black cowboy and amateur naturalist from Texas, discovered deeply buried fossil bison bone beds near Folsom, New Mexico. It was not until 1927, more than four years after his death, that the Folsom site was formally excavated, and chipped stone tools were recovered in direct association with fossilized bones from extinct bison. During the early to mid-twentieth century, many citizens participated in federal archaeology programs across the United States, including many African American men and women. From our perspective as editors of important publication series in archaeology, the roles of African Americans in this and other episodes in the history of our field are underappreciated. We recognize the growing number of contemporary Black scholars in the field and their significant contributions, some of which are highlighted at the Society of Black Archaeologists website (https://www.societyofblackarch aeologists.com/).

Currently, none of the editors of SAA publications are Black or Indigenous, and there are few BIPOC members on our editorial boards. This is unacceptable. In the past, some of our journals have not considered historical archaeology as seriously as we should, including its contributions to knowledge about how BIPOC lives matter in the past and present. We have not done enough to create room for their voices and viewpoints in our publications. We must change these situations.

To initiate these changes, and to combat racism in archaeology and in contemporary society more broadly, we are committing to be more inclusive of Black scholars and others from underrepresented communities by vowing to undertake the following actions:

(1) Include BIPOC members on SAA editorial boards and committees and strive to incorporate BIPOC perspectives in committee decisions, acknowledging the guidance they are already transmitting in how to create anti-racist organizational culture.

(2) Encourage BIPOC scholars to become editors of our journals when there are openings.

(3) Include more archaeology of the recent past and colonialism in our journals through the encouragement of BIPOC scholars and publication of their and others' papers.

(4) Strive to make our publications attractive venues for BIPOC scholars to publish their work by diversifying the scope and content of our publications.

(5) Invite BIPOC scholars to serve as peer reviewers for manuscripts submitted to SAA publications.

(6) Commit to the respectful treatment of BIPOC and non-Western authors by committee members, reviewers, and ourselves.

(7) With their permission, elevate publications by BIPOC authors in social media and public media outlets.

(8) Promote archaeological knowledge as a tool for combating racism and structural inequality and encourage discussion of how these affect the practice of archaeology.

(9) Promote diverse viewpoints and voices in the vision of what archaeology can be and how archaeology is practiced.

(10) Advocate to the SAA board that awards be created in honor of Black scholars in archaeology.

Lynn Gamble, Editor, American Antiquity

Debra Martin, Incoming Editor, American Antiquity

Julia Hendon, Editor, Latin American Antiquity Calogero Santoro, Editor, Latin American Antiquity Sarah Herr, Editor, Advances in Archaeological Practice 
Christina Rieth, Editor, Advances In Archaeo- Christopher Rodning, Editor, The SAA logical Practice

Archaeological Record

Sjoerd van der Linde, Editor, Advances in Arch- $\quad$ Michelle Hegmon, Past Editor, The SAA Press aeological Practice

Jennifer Birch, Editor, The SAA Press 